\section{ACCOMMODATIONS BEST SERVED SOFT: SUPPORTING THE NEEDS OF DISABLED YOUNG ADULTS IN THE WORKPLACE}

\begin{abstract}
${ }^{1,2}$ Arif Jetha*, ${ }^{1}$ Julie Bowring, ${ }^{3}$ Adele Furrie, ${ }^{4}$ Frank Smith, ${ }^{1,2,5}$ Curtis Breslin. ${ }^{1}$ Institute for Work and Health, Toronto, Canada; ${ }^{2}$ Dalla Lana School of Public Health University of Toronto, Toronto, Canada; ${ }^{3}$ Adele Furrie Consulting; ${ }^{4}$ National Eduation Association for Disabled Students; ${ }^{5}$ Seneca College, Toronto, Canada
\end{abstract}

\subsection{6/oemed-2018-ICOHabstracts. 1610}

Introduction A disability may add to the challenges faced by young adults during the school-to-work transition. Few studies have examined differences in soft (e.g., scheduling modification) and hard accommodation need (e.g., ergonomic adaptation) among disabled young adults, and the factors associated with accommodation need.

Methods An online survey was conducted of 155 Canadian disabled young adults (mean age $=25.8 \pm 5.1$ ). Respondents were either employed or seeking employment, and recruited using a registry from a national disability organisation. Respondents were asked about their need for 16 soft and hard accommodations. Demographic (e.g., gender), health (e.g., disability type, work limitations), and work characteristics (e.g., work status, hours worked/ week, permenant vs short-term contract) were collected. Participants were also asked about perceived barriers to accessing accommodations using eight items (e.g., disclosure difficulites, cost of accommodation). Multivariable logistic analyses were conducted to examine the factors associated with soft and hard accommodation need.

Result Most participants reported psychological (79\%) and learning disabilities (45\%), and $68 \%$ had $>1$ disability. Over half $(55 \%)$ were employed at the time of the survey, and $80 \%$ worked in non-standard employment conditions (e.g., part-time or short-term work). An average of five perceived accommodation barriers were indicated. More soft accommodations (mean $=6.3,95 \% \mathrm{CI}: 6.00$ to 6.30 ) were needed than hard accommodations (mean $=4.9,95 \% \mathrm{CI}$ : 4.60 to 5.20 ). Soft accommodation need was associated with less perceived accommodation barriers ( $\mathrm{OR}=-0.83,95 \% \mathrm{CI}: 0.73$ to 0.94$)$, not working $(\mathrm{OR}=-0.39,95 \% \mathrm{CI}$ : 0.16 to 0.91$)$ and greater work limitations $(\mathrm{OR}=1.1,95 \% \mathrm{CI}$ : 1.01 to 0.12$)$. Hard accommodation need was associated with less perceived accommodation barriers (OR $=-0.88,95 \% \mathrm{CI}: 0.78$ to 0.99$)$.

Discussion Offering soft accommodations may be a particularly important strategy for organisations to support the employment of disabled young adults. Interventions that address perceived barriers to accessing accommodations may result in a greater requirement for workplace supports that benefit the school-to-work transition.

\section{INVESTIGATING THE EFFECTIVENESS OF ORGANISATIONALLEVEL INTERVENTIONS FOR THE MANAGEMENT OF WORK-RELATED STRESS THROUGH A PROCESS EVALUATION: AN ITALIAN CASE STUDY}

C Di Tecco, M Ronchetti, M Ghelli, B Persechino, S lavicoli. INAIL - Italian Workers Compensation Authority. Department of Occupational and Environmental Medicine, Epidemiology and Hygiene

\subsection{6/oemed-2018-ICOHabstracts. 1611}

Introduction Evaluating the effects of organisational level interventions, as those related to work related-stress, is broadly recognised crucial to identify the key steps needed to ensure the efficacy of interventions. The Italian Workers' Compensation Authority (INAIL) developed a methodology for management of risks associated to work related-stress as an organisational integrated approach useful for OSH professional and companies. This study provides a process evaluation of organizational-level work related stress management interventions in a public administration using the INAIL's methodology.

Methods An Italian Public Administration (more than 4, 000 employees) has carried out a process of risk assessment and management of work-related stress using the INAIL's approach and tools, with the methodological support of a research team form INAIL. Our support ensured that some key aspects of the process were implemented such as: specific training, the active involvement of workers, and OSH professionals, and raise the awareness of management on the importance of organisational level interventions in managing stress at work. According to the literature, we analysed intervention process using two methodological approaches: quantitative and qualitative.

Results Some aspects resulted valuable for the effectiveness of the interventions: the active role played by OSH professionals in implementing the process; 2) the high participation of workers with a $75 \%$ of response rate in the risk assessment (3200 questionnaires); 3) The direct involvement of the management; 4) a bottom-up approach through the active involvement of workers by the means of focus groups in identifying concrete actions based on the assessment findings in collaboration with $\mathrm{OSH}$ professional and managers.

Discussion This study investigates the ways of implementing an effective integrated approach for assessing and managing work related stress using the INAIL's methodology through a process evaluation of organizational-level interventions. Findings contributes to the international debate on how to verify the effectiveness of processes of intervention planning and implementation.

\section{PSYCHOSOCIAL FACTORS IN THE WORKPLACE. INTERACTIONS BETWEEN DEPRESSION AND STRESS COMPARED WITH LIFE STYLE RISK FACTORS}

Javier Naveros*, Sergio Orlandini Cappannari, Maria Cecilia Colautti. Argentinean Association of Health Promotion, Buenos Aires, Argentina

\subsection{6/oemed-2018-ICOHabstracts. 1612}

Introduction As the World Health Organisation has noted, four chronic illnesses, cardiovascular, diabetes, cancer and respiratory illnesses, are responsible for more than 60\% of the world's deaths. We know that persons with these chronic illnesses have much higher rates of depression and anxiety than the general population. Major depression among persons experiencing chronic medical conditions increases the burden of their physical illness and somatic symptoms, causes an increase in functional impairment, and increases medical costs.

Methods Our survey covers a wide range of lifestyle and health issues pertinent to adults employed in companies of the service and the industrial sector. The information analysed consists of 8000 people from different companies all over Latin America. Different risk level groups for depression and stress are compared with life style risks, health risks factors and morbid conditions (arterial tension levels, weight, exercise, eating habits, smoking and alcohol use).

Result 222 people presented very high stress rating, 816 with high stress rating, 4241 with moderate stress rating. We find that in the high-risk group for stress, all life style risk were 
similar at about 4\%, but moving towards high risk group for stress, we find that unhealthy eating was the higher life style risk reaching a $20 \%$, followed by smoking and alcohol consumption at $18 \%$. This trend was more notable for the moderate stress risk group where unhealthy eating reached a $60 \%$ and alcohol, smoking and sedentary was tight at 63\%. More than half of the population taking the wellness checkpoint survey presented some type of unhealthy life style risk. For the 2340 screened people for depression, 21 were found to have risk for severe depression, 43 people had risk for moderate depression and 239 people had risk for mild depression. For the high-risk group, we found alcohol consumption risk as the leading one in $8 \%$ followed by $7 \%$ of smoking. This trend can be seen better in the high and moderate risk group for depression, where alcohol consumption risk is $18 \%$ and $17 \%$ for smoking. For the mild risk group is $38 \%$ for alcohol consumption and $36 \%$ for smoking and unhealthy eating.

Discussion From this first analysis, we observed interrelations that can contribute to open the perspectives in understanding of aetiology and pathogenical aspects, co-morbilities and treatments resources for stress and depression.

\section{ASSOCIATION BETWEEN PERCEIVED DEMANDS AND BARRIERS AND WORK-RELATED STRAIN IN SCHOOL- TEACHERS IN CHUQUISACA, BOLIVIA}

${ }^{1}$ María Teresa Solis-Soto*, ${ }^{2}$ Anabel Schön, ${ }^{2}$ Manuel Parra, ${ }^{2}$ Katja Radon. ${ }^{1}$ Universidad Mayor, Real y Pontificia de San Francisco Xavier de Chuquisaca. Sucre-Bolivia; ${ }^{2}$ Center for International Health, University Hospital Munich (LMU). Munich- Germany

\subsection{6/oemed-2018-ICOHabstracts. 1613}

Introduction Teaching environments can influence performance and health of teachers. In Latin America little research was done to explore teaching conditions and health. The objective was to assess demands and barriers for teaching and workrelated strain in school-teachers in Chuquisaca, Bolivia.

Methods Cross-sectional study was conducted in sixty randomly selected schools (August to November 2015). All teachers (1062) were invited to participate (response 56\%).

Teaching demands and barriers were explored through a set of questions previously used by UNESCO-OREALC (4-points Likert scales). Demands included sociocultural differences, indiscipline, learning problems, desertion, and repetition. Barriers explored about lack of student families and colleagues support, poor social and economic conditions, lack of pedagogical support and leadership of the director. A validated version of the irritation index (7points Likert scale) was used to explore work-related strain (emotional and cognitive irritation). Scores for demands, barriers and irritation were added and dichotomized in lower (1 st and 2nd) and upper ( $3 \mathrm{rd})$ tertiles.

Crude and adjusted odds ratios with 95\% confidence intervals for work-related strain were estimated through logistic regression models. Missing data was imputed using chained equations imputation method. Sensitive analysis was performed using imputed and non-imputed data.

Results Most of teachers were female (72\%), in public schools $(81 \%)$, exclusively in primary level $(48 \%)$. About one-third of teachers $(37 \%)$ have bachelor or postgraduate training $(37 \%)$. Teaching in primary level (adjusted OR 2.21; 95\% CI: 1.4 to $3.6)$ and high academic barriers $(1.73 ; 1.1-2.8)$, were statistically significant risk factors for work-related strain. University graduated teachers had lower risk $(0.6 ; 0.4-0.9)$.
Discussion Structural barriers seem to play an important role in work-related strain in teachers, while they are able to cope with pedagogical demands. Comprehensive actions need to be taken considering families and social resources in order to take care of teachers' physical and mental health for a better performance.

\section{IMPACT OF OCCUPATIONAL STRESS IN ITALIAN OFFSHORE OIL INSTALLATION WORKERS AND CYTOKINES HOMEOSTASIS}

${ }^{1} \mathrm{~L}$ Di Giampaolo, ${ }^{1} \mathrm{E}$ Costantini, ${ }^{1} \mathrm{C}$ D'Angelo, ${ }^{1} \mathrm{~F}$ Frassanito, ${ }^{2} \mathrm{M}$ Di Gioacchino, ${ }^{1} \mathrm{M}$ Di Nicola, ${ }^{1} \mathrm{M}$ Reale. 'Department of Medical, Oral and Biotechnological Sciences, University 'G. D'Annunzio', Chieti, Italy; ' Department of Medicine and Science of Ageing, University 'G. D'Annunzio', Chieti, Italy

\subsection{6/oemed-2018-ICOHabstracts. 1614}

Introduction Environmental, behavioural and psychological stimuli can activate inflammation. Psychosocial factors such as work demands and decision latitude, social support, and psychological distress, play important roles in the development of inflammatory status. We conducted a study on occupational stress and its influence on cytokines homeostasis in Italian offshore oil installation workers.

Methods Enrolled workers from an offshore oil company were divided into two groups, which took rotations of four weeks to work on the platforms at sea. The onshore and offshore groups were broadly the same in terms of their ranking, work experience, age, and distribution of job categories. All subjects complete a self- administered questionnaire collecting information on socio-demographic characteristics, occupational stress, sleep disorders, and past injuries. The salivary cortisol and serum cytokines levels were measured by ELISA, cytokines gene expression was evaluated by Real-time PCR.

Results Salivary cortisol concentrations were significantly increased confirming the effectiveness of occupational stress. In fact, in our workers, cortisol level was directly correlated to job insecurity, State-Trait Anxiety (STAI-1), shift work and inversely proportional to sleep quality. In addition, we observed a direct correlation also between BMI and cortisol level. A significant increase of TNFa and a weak elevation of IL-10 level were observed in the offshore group. To examine whether changes in cytokines levels were due to changes in cell type composition, a reduction of ratio between lymphocyte percentages and neutrophils percentages (Ly/Ne\%) were observed. Spontaneous expression of IL-1b, TNFa and IL-10 were higher in offshore respect to onshore workers. The increase in all PHA-induced cytokine release was significantly higher in the offshore workers. Only TNFa was significantly higher in LPS-stimulated PBMC of offshore workers.

Conclusion Taken together, the current study revealed that occupational stress not only activates neuroendocrine stress systems, but also influence cytokines homeostasis.

\section{MEASURING THE FACTORS ASSOCIATED WITH THE OCCUPATIONAL WELLBEING OF NURSES WHO PROVIDE PALLIATIVE AND END OF LIFE CARE}

${ }^{1} \mathrm{KL}$ Penz, ${ }^{2} \mathrm{D}$ Goodridge, ${ }^{3} \mathrm{~L}$ Hellsten. ${ }^{1}$ Assistant Professor, College of Nursing, University of Saskatchewan, Regina, Saskatchewan, Canada; ${ }^{2}$ College of Medicine, University of Saskatchewan, Saskatoon, Saskatchewan, Canada; ${ }^{3}$ College of Education, University of Saskatchewan, Saskatoon, Saskatchewan, Canada

10.1136/oemed-2018-ICOHabstracts. 1615 